\title{
Fate of metabolic hydrogen in the rumen
}

\author{
By J. W. Czerkawski, Hannah Research Institute, Ayr KA6 $5 \mathrm{HL}$
}

\section{Introduction}

The first axiom of ruminology appears to be: "The rumen is a strictly anaerobic system' (Hungate, I966) but before we accept this we should examine the evidence for and against this assertion. Probably the strongest evidence for anaerobiosis comes from the studies of the reactions in the rumen, from the stoichiometries observed and from the low oxidation-reduction potential obtaining in the rumen, although some discrepancies exist (Seeley, Armstrong \& MacRae, I969; Demeyer, Nevel, Henderickx \& Martin, 1970). Many important rumen organisms grown in pure culture are sensitive to oxygen, but the isolated microbes, apart from being separated by countless generations from the original inocula, might behave quite differently in their natural habitat. The evidence that the rumen might be a partially aerobic system is not conclusive, but plentiful. It can be easily demonstrated in vitro that the rumen contents can utilize oxygen with an alteration of the fermentation pattern but with no inhibition of the rate of utilization of substrates (Czerkawski $\&$ Breckenridge, 1969). The rumen contents are surrounded by tissues rich in capillaries containing blood with high-oxygen tension compared with the oxygen tension in the rumen which is never more and rarely less than $1 \%$ (see review, Czerkawski, I969). Facultatively anaerobic micro-organisms exist in the rumen and there is evidence of some processes in the rumen that are more common under aerobic conditions, such as oxidation of $n$-alcohols (Czerkawski \& Breckenridge, 1972) or desaturation of long-chain acids (Patton, McCarthy \& Griel, r968; Sklan, Volcani \& Budowski, I97I).

The metabolic hydrogen and possibly oxygen are of vital importance in the energy exchanges in the rumen, and any attempt to manipulate this balanced ecosystem to increase the efficiency of feed conversion, must take the fate of hydrogen and the possible participation of oxygen into consideration.

\section{Examples of reactions involving the movement of metabolic hydrogen}

Glycolysis and methanogenesis. Quantitatively, carbohydrates are the most important substrates in the rumen and the glycolytic pathways are well documented (Barnett \& Reid, I961; Stadtman, 1967). About $80 \%$ of the dietary hexose converted to volatile fatty acids is converted to acetic and butyric acids with net production of hydrogen, and this leaves an excess of hydrogen, which would accumulate if it were not used by the methane bacteria to reduce carbon dioxide to methane. Numerous $3 \times(2) 5$ 
studies here and elsewhere (see Czerkawski, ig69) have shown that it is possible to inhibit methane production both in vivo and in vitro. Remembering that $4 \mathrm{~mol}$ of hydrogen are required to produce $I \mathrm{~mol}$ of methane and bearing in mind that the calorific value of methane is about 3.5 times that of hydrogen - in terms of energy lost by the host animal - the inhibition would result in no gain. Fortunately, the rumen ecosystem is adaptable and the net accumulation is invariably much less than the theoretical amount (Bauchop, 1967). The hydrogen is rechannelled to other processes. The measurement of the extent of the known processes that require hydrogen such as the usual increase in the production of propionic acid or the biohydrogenation of unsaturated fatty acids, show that these processes can account for only a small proportion of the saved hydrogen.

Metabolism of alcohols. The primary alcohols are not quantitatively important as substrates for rumen micro-organisms and yet they are metabolized by the rumen organisms and must be taken into consideration. Methanol forms a small proportion of ruminant diet in pectin and small amounts of ethanol occur in the rumen under certain dietary conditions (Allison, Dougherty, Bucklin \& Snyder, 1964). Both these alcohols, as well as propanol and butanol, are oxidized by the rumen contents in vitro (Czerkawski \& Breckenridge, 1972) and in vivo (Fredericksen \& Ochia, I970). The products are the corresponding acids and methane except with methanol which, by analogy, might be converted to formic acid which is dissimilated rapidly in the rumen and results in methane production (Carroll \& Hungate, 1955). The oxygen for the oxidation of alcohols is probably derived from water, leaving excess of hydrogen that gives rise to stoichiometric amounts of methane. Although the oxidation of $n$-alcohols is slow compared with the rate of dissimilation of hexose, its existence indicates that the rumen micro-organisms might possess enzymes that can carry out the reverse process, particularly when there is an excess of hydrogen.

Fermentation of rhamnose and 1,2-propanediol. Rhamnose occurs widely but in small amounts in plants, in animal tissues and in micro-organisms; its fermentation pattern is different from that of hexoses and pentoses. The main products of fermentation of rhamnose are acetic and propionic acids together with variable

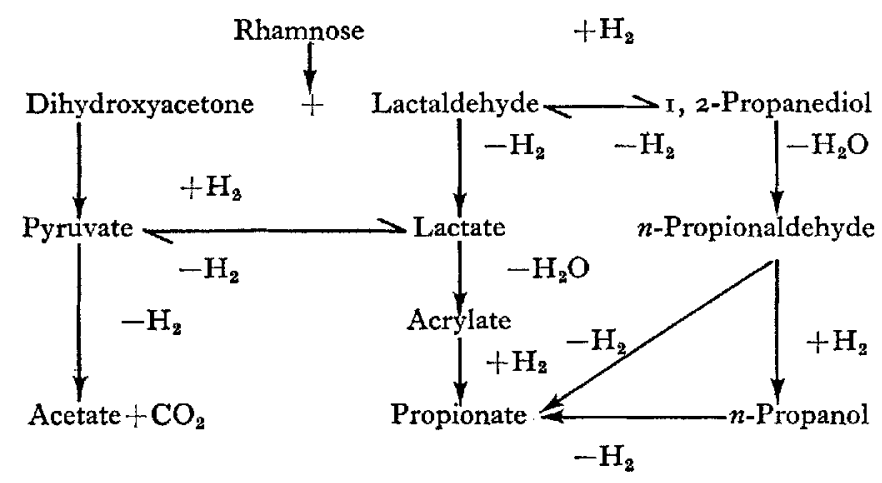


amounts of lactic acid and $n$-propanol. Neither butyric acid nor methane are produced. When I,2-propanediol is fermented the main products are $n$-propanol and propionic acid, and there is a temporary accumulation of propionaldehyde. It appears that the fermentation pathways of rhamnose and 1,2-propanediol are related.

Although the rumen micro-organisms are capable of metabolizing $n$-propanol, it is unlikely that this reaction contributes markedly to total fermentation when I,2-propanediol is the substrate. However, the dihydric alcohol is a sufficiently strong acceptor of metabolic hydrogen to compete with the methanogens and cause small $(10-30 \%)$, but consistent, inhibition of endogenous methane production. This is small compared with the inhibition that can be obtained with chloroform or long-chain fatty acids, but it should be remembered that I,2-propanediol and the end-products of its fermentation (propionic acid and $n$-propanol) are glucogenic. In view of the limited ability of the lower intestinal tracts of ruminants to deal with hexoses (Ørskov, Mayes \& Penn, 1971), the value of I,2-propanediol in the manipulation of rumen fermentation should not be underestimated.

Lipid metabolism. The biohydrogenation of the dietary unsaturated fatty acids has been studied extensively (see Garton, 1967). Although this process does not appear to contribute direct to the energy exchanges in the rumen, it is of importance, because, being inhibitors of methane production the fatty acids might affect the general fermentation pattern (Blaxter \& Czerkawski, I966). The biohydrogenation of unsaturated fatty acids - and in particular the octadecadienoic acid, linoleic - is also important because of the essential nature of this acid in nutrition of both the simple-stomach and ruminant animals (Moore, Noble, Steele \& Czerkawski, 1969). The recent reports of desaturase activity in the rumen are of interest in this connexion (Sklan et al. 1971), and demonstrate again yet another example of movement of metabolic hydrogen and possible participation of oxygen in rumen reactions.

The formation of branched-chain fatty acids and those with odd carbon numbers in the rumen, acids not found in the diet, prove conclusively that there is a net synthesis of fatty acids in the rumen and that the microbes are capable of carrying out such a process. Results of direct measurements in sheep (Ørskov, Fraser \& McDonald, I97 I) show that there is a synthesis of lipid in the rumen, which could amount to ro-20 $\mathrm{g} / \mathrm{d}$ in sheep receiving about $22 \mathrm{~g}$ fat in their ration. Such synthesis would require about 10 $1 / \mathrm{d}$ of hydrogen. The amounts of metabolic hydrogen used in hydrogenation of dietary fatty acids are smaller $(3 \mathrm{l} / \mathrm{d})$.

Other examples. Apart from the main constituents (protein, carbohydrate and lipid), the diet of the ruminant animals contains other substances that might contribute to metabolism in the rumen as well as the metabolism of the host animal. For instance, glycerol, an important constituent of dietary lipids is supposed to be converted to pyruvic acid by the usual pathways, yet by analogy with the metabolism of 1,2 -propanediol discussed above, it is possible that some of it might be dehydrated to $\beta-\mathrm{OH}$-propionaldehyde, which in turn might be converted to $\beta$ $\mathrm{OH}$-propionic acid and I,3-propanediol.

Another example to illustrate the importance of minor food constituents arises from observations that, in certain regions of Australia, sheep on pasture consume 
alkaloids-particularly heliotrins. These substances interfere with nucleic acid metabolism and seriously reduce the liver function of these animals. These alkaloids are cleaved reductively in the rumen, but the process is inefficient because of competition for metabolic hydrogen by the methane bacteria (Lanigan, 1971). It is of interest in connexion with this discussion that the inhibition of methane production by chloroform increases the extent of the reductive cleavage of the alkaloids and thus could be useful in detoxification.

\section{Significance of metabolic hydrogen in the manipulation of rumen fermentation}

Is it possible that a ruminant animal can control its own fermentation in general, and the movement of metabolic hydrogen in particular? The ruminant can, albeit involuntarily, control the conditions in the rumen by the changes in the rate of secretion of saliva and possibly by changing the rate of flow of digesta. The rumen movement may also be important in this as well as the act of rumination, inasmuch as they facilitate mixing of digesta. If it can be assumed that oxygen diffuses into the rumen from the blood supply and that it is important in the energy metabolism of the microbes, what is the contribution of rumen movement and chewing the cud to this process?

No doubt it is possible to control the movement of metabolic hydrogen and ipso facto fermentation patterns in the rumen indirectly, by the choice of diet, but this is discussed elsewhere in this symposium. Here, only two types of approach will be considered; inhibition of methane production using specific food additives and possible utilization of alternative acceptors of metabolic hydrogen.

Many inhibitors of methane production exist, but only some of these might be useful in the control of rumen fermentation. The unsaturated and some saturated fatty acids inhibit methane production specifically inasmuch as they do not lead to a marked depression of the digestibility of the basal rations (Czerkawski, Blaxter \& Wainmann, I $966 a, b)$. There is no accumulation of hydrogen, but the hydrogen used in biohydrogenation can account for only a small proportion of hydrogen saved from methanogenesis. Like most inhibitors of methane production, the fatty acids change the rumen fermentation pattern in favour of propionic acid and nearly $80 \%$ of added fatty acids are retained by the host animal. On the other hand, some trihalogen methane analogues, particularly chloroform, are powerful inhibitors and can be used in very small amounts (Bauchop, 1967 ; Czerkawski \& Breckenridge, 1970; Harfoot \& Czerkawski, 197I; Trei, Parrish, Singh \& Scott, 1971). The chloroform inhibition of methane production in sheep is accompanied by accumulation of hydrogen gas (less than $15 \%$ of the theoretical) and by an apparent increase in heat production, as judged by an increased oxygen uptake. The last observation is not unexpected, since the rechannelling of the spared hydrogen must result in more reduced end-products of fermentation, which would require more oxygen to be metabolized by the host animal.

It is of interest in this connexion, to consider the inhibition of methane production by oxygen (Czerkawski \& Breckenridge, I969). It can be shown in experiments in vitro that the volume of oxygen taken up is equal to approximately half the 
volume of unaccounted hydrogen, and this suggests that oxygen might be an acceptor of hydrogen in the rumen. The reaction $\mathrm{H}_{2}+\frac{1}{2} \mathrm{O}_{2} \rightarrow \mathrm{H}_{2} \mathrm{O}$ will no doubt increase heat production, but it also results in the production of 2 mol of ATP. Adding oxygen to the rumen by bubbling has so far not proved successful, but depending on the desired results it is possible to use other acceptors of hydrogen. For instance, if it is desired that the propionate production should increase then propanediol is the additive of choice. One can visualize a situation in which the methane production is inhibited with chloroform and this is supplemented with propanediol. On the other hand, it might be required to increase the production of acetic acid without changing the production of propionic, then a possible acceptor would be nitrate. This would give rise to ammonia (Demeyer \& Henderickx, 1967).

\section{Concluding remarks}

Although it is not possible to propose a unified theory about the movement of metabolic hydrogen on the basis of the arguments enumerated above, there should be no doubt that the metabolic hydrogen and possibly oxygen are of importance in the control of rumen fermentation.

The rumen is a complex ecosystem, but it can be better defined in terms of input and output measurements than can many other ecosystems, such as lakes, forests or estuaries. Successful mathematical models have been developed for the large systems and there is no reason why this should not be done with the rumen. Such models will become increasingly necessary when the knowledge and complexity of the various interactions increase. Some attempts have been made already (Hungate, I965; Baldwin, Lucas \& Cabrera, 1969) to devise models for the rumen. Some of these have predictive properties that might be valuable in the manipulation of rumen fermentation, particularly when one considers the fate of such a common 'currency' as hydrogen.

\section{REFERENCES}

Allison, M. J., Dougherty, R. W., Bucklin, J. A. \& Snyder, E. E. (1964). Science, N.Y. r44, 54.

Baldwin, R. L., Lucas, H. L. \& Cabrera, R. (1969). In Physiology of Digestion and Metabolism in the Ruminant p. 320 [A. T. Phillipson, editor]. Newcastle upon Tyne: Oriel Press Ltd.

Barnett, A. J. G. \& Reid, R. L. (1961). Reactions in the Rumen. London: Arnold.

Bauchop, T. (1967). F. Bact. 94, 17 I.

Blaxter, K. L. \& Czerkawski, J. W. (1966). F. Sci. Fd Agric. 17, 417.

Carroll, E. J. \& Hungate, R. E. (I955). Archs Biochem. Biophys. 56, 525.

Czerkawski, J. W. (1969). Wld Rev. Nutr. Diet. I1, 240.

Czerkawski, J. W., Blaxter, K. L. \& Wainman, F. W. (1966a). Br. F. Nutr. 20, 349.

Czerkawski, J. W., Blaxter, K. L. \& Wainman, F. W. (1966b). Br. F. Nutr. 20, 485.

Czerkawski, J. W. \& Breckenridge, G. (1969). Br. F. Nutr. 23, 67.

Czerkawski, J. W. \& Breckenridge, G. (1970). Lab. Pract. 19, 7I7.

Czerkawski, J. W. \& Breckenridge, G. (1972). Br. \%. Nutr. 27, 131.

Demeyer, D. \& Henderickx, H. (1967). Archs int. Physiol. Biochim. 75, 157.

Demeyer, D., Nevel, C. van, Henderickx, H. \& Martin, J. (1970). Publs Eur. Ass. Anim. Prod. no. 13, p. 37.

Fredericksen, J. H. \& Ochia, B. A. (1970). Acta Agric. scand. 20, 17.

Garton, G. A. (r967), Wld Rev. Nutr. Diet. 7, 225.

Harfoot, C. G. \& Czerkawski, J. W. (I971). Proc, Nutr. Soc. 3o, 44A.

Hungate, R. E. (1965). In Physiology of Digestion in the Ruminant p. 8 [R. W. Dougherty, editor]. Washington DC: Butterworths. 
Hungate, R. E. (r966). The Rumen and Its Microbes p. ro. New York and London: Academic Press. Lanigan, G. W. (1971). Aust. F. agric. Res. 22, 123.

Moore, J. H., Noble, R. C., Steele, W. \& Czerkawski, J. W. (rg69). Br. F. Nutr. 23, 869.

Ørskov, E. R., Fraser, C. \& McDonald, I. (197 I). Br. f. Nutr. 26, 477.

Ørskov, E. R., Mayes, R. W. \& Penn, A. (1971). Proc. Nutr. Soc. 30, 43 A.

Patton, R. A., McCarthy, R. D. \& Griel, L. C. (I968). F. Dairy Sci. 5r, т3 го.

Seeley, R. C., Armstrong, D. G. \& MacRae, J. C. (1969). In Energy Metabolism of Farm Animals p. 13 [K. L. Blaxter, J. Kielanowski and G. Thorbek, editors]. Newcastle upon Tyne: Oriel Press Ltd.

Sklan, D., Volcani, R. \& Budowski, P. (I97I). \%. Dairy Sci. 54, 5 I5.

Stadtman, T. C. (1967). A. Rev. Microbiol. 2I, I2 I.

Trei, J. E., Parrish, R. C., Singh, Y. K. \& Scott, G. C. (1971). F. Dairy Sci. 54, 536. 